\title{
Object-Based Analysis of Multispectral RS Data and GIS for Detection of Climate Change Impact on the Karakoram Range Northern Pakistan
}

\author{
Waquar Ul Hassan Chaudhary ${ }^{1}$ and Åke Sivertun ${ }^{2}$ \\ 1. Department of Tema, Linköping University, Linköping 58183, Sweden \\ 2. Department of MVI/MTA, Swedish Defence University, Stockholm 11593, Sweden
}

\begin{abstract}
Changing climate has a great impact on northern area of Pakistan's environment and is more prone to environmental changes impacts than rest of the country due to its high elevation. However, melting glaciers effect not only the local environment but also the whole country with frequent and heavy floods. Remote sensing (RS) from Satellites and Airplanes used in Geographical Information Systems (GIS) are technologies that can aid in understanding the on-going environmental processes. Furthermore, help researchers to observe, understand, forecast and suggest response to changes that occur. It can be natural disasters or man-made disasters and human induced factors. Still analysis accuracy issues play a vital role for the formulation of any strategy. To achieve better results, object based analysis methods have been tested. Various algorithms are developed by the analysts to calculate the magnitude of land cover changes. However, they must be evaluated for each environment that is under observation as mountainous areas. Here were object-based methods evaluated in comparison with pixel based. Landslides, soil moisture, soil permeability, snow cover and vegetation cover can be effectively monitored by those methods.
\end{abstract}

Key words: Geographical information systems, spatial data analysis, object-based analysis of remote sensing data, glacier degradation in Karakoram, vegetation and snow cover.

\section{Introduction}

Massive scale disturbance in topological, morphological, meteorological, hydrological and biological phenomena that cause considerable change to the environment reported in the Karakoram Range Northern Pakistan. Detection, forecasting, planning and management play an important role for the conservation and reduction of the prevailing environmental threats. For this purpose, availability, accuracy and reliability of spatial data is considered as the most important factors [1]. Data collection, analysis, interpretation and presentation are the basic domains of geo-informatics as a subject. This is important as mankind is living in an era of revolution in space or satellite imaging techniques for data acquisition and quick sharing of authentic information [2].

Corresponding author: Åke Sivertun, professor, research field: geoinformatics. E-mail: ake.sivertun@fhs.se.
Historically, 18 major flooding events have occurred in Pakistan in the Indus down stream areas since 1935. From these ten worst flooding events (1992, 1993, 1994, 1995, 1996, 2001, 2003, 2005, 2008 and 2010) observed during last twenty years, it is including the most recent 2010 flooding [3]. Glacier retreat phenomena are another alarming sign in global warming and regional climate change context and such retreat lead to development of glacial lakes in those particular retreated regions [4].

Medium resolution imagery, as Landsat TM and ETM imagery, is considered as more effective for the analysis of such land cover changes that have occurred on vast areas [5]. There are about 5,218 glaciers that are located on the $15,040 \mathrm{~km}^{2}$ area of Pakistan, providing $50 \%$ to $80 \%$ of the fresh water during summer snow melting season. North Pakistan that has one of the world's most difficult terrains to reach is 
the hub of three very well known mountain systems, Hindu Kush, Himalaya and Karakoram [6]. Studies show that about 2,500 glacial lakes have been formed during the last few decades due to rapid snow melt [6, 7]. These glacial lakes are more prone to outburst phenomena that may lead to immense damage to human settlements, agriculture land and live stock. It has also concluded that the last decade (2001-2010) was the warmest for Karakoram Himalaya region in the national history by comparing it with meteorological data from the past three decades 1971-2000 [6]. About $13 \%$ of the total area of Pakistan comprises of glaciers but recent research shows that $13,700 \mathrm{~km}^{2}$ glacial zones would disappear by 2035 due to global climatic change effects (Fig. 1). Statistical data collected from these different sources shows the numbers of affected population from natural disasters, specially flooding, landslides and avalanches etc. during the last two decades. These numbers are much higher than previous six decades [8].

\subsection{Problem Statement}

Five major glacial lake outburst flooding events occurring in Hunza River Basin Gojal were reported during the period 2007-2008 [9].

Northern glaciers of Pakistan is considered as the life line for Pakistani agriculture based economy because almost all water from these glaciers are used to irrigate the fertile lands from province Punjab to Sindh and Baluchistan. During the last few years' rare phenomena, like the Atta-Abad artificial lake incident on Hunza River due to a combination of flood and landslides. Changes in vegetation cover also could partly explain such extreme events. Knowledge about where and how the change in glaciers occurs is essential to take counter measures and prepare against floods and other potential dangerous incidents. Analyse methods through remote sensing is here suggested to overcome the problems in monitoring the high mountains that are affected by the climate change and changing hydrological regimes.
Table 1 Glacier depletion record survey [23].

\begin{tabular}{lcl}
\hline Glacier & $\begin{array}{l}\text { Depletion ratio } \\
(\% \text { area })\end{array}$ & Study period \\
\hline Batura & 15 & $1992-2001$ \\
Biafo & 9.0 & $1992-2000$ \\
Yazghil & 5.0 & $1992-2007$ \\
Jutmau & 28 & $1992-2007$ \\
Passu & 7.0 & $1992-2008$ \\
Ghulkin & 12 & $1992-2008$ \\
\hline
\end{tabular}

\subsection{Aim of the Study/Objectives}

The specific aim of this study is the detection and observation of change of ice, snow and vegetation cover over the last twenty years for the Karakoram range using satellite images as suggested by Gamanya et al. and Khalsa et al. [9, 10].

The specific objectives of this study are:

(1) Analysis of climate change impact using GIS and Satellite data for the study area;

(2) Investigating methods to analyse vegetation, ice and snow using both object and pixel based techniques and spectral bands combinations;

(3) Surface changes like landslides, soil erosion/land erosion, glacial lake formation and lake outburst phenomena;

(4) Investigate the two major types of methods to calculate the changes to the different mountainous land scape objects like change enhancement methods and change information extraction algorithms [11].

\section{Materials}

\subsection{Data and Methods}

There are different types of remotely sensed data available on different spectral resolution - up to 200 spectral wave bands between 0.4-2.5 $\mu \mathrm{m}$ [12]. For this study, Landsat thematic and enhanced thematic mapper imagery is used because of its availability during the research period. Furthermore, the scenes are easily obtained directly from United States Geological Survey and University of Maryland. For the elevation model analysis, SRTM data with a resolution of 3 arc nodes was obtained from the same 
portal for this study.

Both pixels and object based analysis methodologies have certain advantages and disadvantages depending on the data used for the study. For example, pixel based technique shows certain flaws at the pixel's spatial scale level [13]. Mixed pixels is another well-known problem occurring during pixel based analysis [13, 14]. Problems with actual representation or size of the real world object and pixel size [13] are few known problems. While, on the other hand, object oriented approach is not good for the analysis of low-resolution imagery. Accuracy in the pixel-based analysis approach can be attained if the object of interest operates at a spatial scale level rather than at the pixels spectral level only $[13,15]$. Therefore, object based analysis is considered more accurate because it possesses the capacity to analyse image objects at several levels including spatial, spectral and temporal [13]. Well-structured object oriented analysis procedures allows the data parameters to be defined by interpreting the object typology and texture information. This is because object texture parameters contain information about spatial relationship that exists among image objects and analysis of variance among neighbouring pixels [16].

\subsection{Object Oriented Image Analysis}

Objects often refer to an individual resolvable entity of an image because it represents the real world phenomena, event or object [10, 17]. Although object based image analysis sometime depends on the low level processing procedures (multi-resolution segmentation) and algorithms by adopting high level classification approach like pattern recognition, knowledge based and fuzzy approaches [18], object typology and texture which are considered as the basic ingredients of accurate analysis [16, 19]. Secondly, unlike the pixel-based analysis approach, newly developed object-based techniques have increased spatial internal variability that extended mapping capabilities in many ways [19]. Segmented areas, image objects or set of homogenous pixels, bears both spatial and spectral properties while on the other hand, it is quite difficult in pixel-based analysis to extract complex information only from spectral mix input or from single pixel $[20,21]$. Object oriented analysis focuses on the representation of meaningful objects in the remotely sensed data that corresponds true spatial pattern unlike traditional approaches where uniform pixels have a unique representative entity [22].

\section{Results and Discussion}

Landsat data analysis clearly indicates that global warming has affected glacier ecosystems of northern Pakistan. Twenty years record portraits that these adverse climatic effects are in the form of snow depletion, landslides, artificial lakes formation and increase in the vegetated land in the area. Meteorological records related to the study area also confirm that global warming has effects on the regional climate of northern Pakistan. Meteorological records archive categorizes 2009 as the top 5th warmest year since 1850 with the decade (2000-2009) recorded as the hottest $[6,23]$. Therefore, a consistent decrease in overall mass balance of glacier snow cover has been observed in the analysis of Landsat imagery of the study area. Esbah et al. [21] categorically explain that after careful study of historical data of Himalayan region, the temperature of this region has been increasing considerably during the last century and it is also currently much higher than average global temperature $[6,21]$. World meteorological organization's technical reports confirm that greenhouse gas-emissions were at their highest level during 2012 and previous decade since 2012 was the warmest in metrological history [23].

In the object-based analysis, various characteristics like colour, shape, compactness and smoothness of the objects are the basic parameters of the segmentation process. Moreover, it also takes accounts to the spectral heterogeneity and homogeneity of image 

Karakoram Range Northern Pakistan

objects. Classification takes segmented image objects at optimal scale level and testifies any classifier either supervised or unsupervised on it for analysis purpose.

Analysis of Landsat imagery clearly depicts the on ground gradual decrease in the natural resources including various non-vegetated classes like ice and snow. Various studies find the receding ratio of Himalayan zone is much faster than any other glacier system on the earth [24]. Interpretation of the analysed data clearly indicates that last ten years were the worst in the history of Karakoram and Himalaya because significant changes in the snow cover over the glaciers which can be clearly observed in the adjacent valleys. These changes brought certain calamities during last few years like the most recent Atta Abad lake incident.

As explained earlier, segmentation provides strong foundation to classification process, Landsat TM and ETM imagery segmentation purpose same parameters of similarity and area. For this study, segmentation parameters selection was primarily based on the careful data handling for best or accurate results by avoiding various flaws like over-segmentation and under-segmentation. Segmented image context file that contain particular set of Landsat TM (Bands1, 4, 5 or Bands 3, 4, 5) and Landsat ETM (Bands1, 4, 5 or Bands 3, 4, 5) images leads to the region extraction stage. In this stage, properties of the regions is analysed on the basis of applied algorithm by using statistical parameters like mean, correlation and standard deviation etc. (Fig. 1).

\subsection{Segmentation and Classification}

For the segmentation of enhanced thematic mapper (Landsat ETM), same parameters of similarity (30) and pixel area (75) algorithm "region growing" were selected.

Landsat imagery object based classification results shows clearly gradual change in the overall mass balance of ice/snow covered in the study area between
1992 and 2012. A consistent and gradual decrease in the non-vegetative classes, particularly in different snow classes (permanent snow, ice, per glacial snow debris and supra-glacial snow debris), was as a regular increase in the vegetation class observed in the area. The reason could be persistent moisture due to snow or ice loss that provides favourable condition for the growth of herbs, shrubs and dwarf plants. Secondly, chances of soil displacement or soil erosion increase in the area due to snow retreat and it also brings various problems to the community because risks of landslide, mudslide and avalanches increased in mountainous region considerably. Classification results of Landsat data (Fig. 2) shows increase in the dry bare land cover class from 1992 to 2012. After analysis of Landsat TM and ETM data Bands 1 (Blue), Band 4 (Near Infrared) and Band 5 (Shortwave Infrared Band) by using Bhattacharya distance classifiers in TM1992 data. The 388,640 features marked as dry bare land that increased to 473,783 features in ETM 2000 data, 890,813 in TM 2011 and 890,989 features in Landsat ETM 2012 data. Such variation or increase also observed in other land cover classes like glacier's rock.

Clear decreases in the other Land cover classes, like ice and permanent snow was observed after analysis. Ice class decreased from 458,769 features in TM year 1992 data while 440,567 in TM year 2011 and 390,961 features in ETM 2012 respectively.

Permanent snow class exhibit similar behaviour and it also decrease gradually except in the year ETM 2000 where as it shows slight variation. From literature review came to know that from the near the year 2000, a strange expansion in Karakoram glaciers mass balance was observed but later in the decade most harsh climatic conditions or warmest weather was observed there. After the analysis of the Landsat bands those are recommended for the exploration of snow and ice cover changes like Band 3 (Red), Band 4 (Near Infrared) and Band 5 (Mid Infra/Shortwave Infrared). 


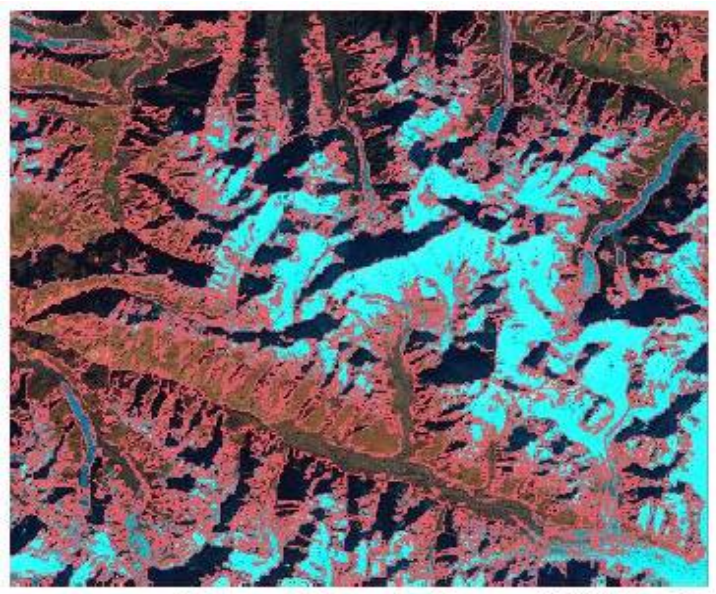

Enhanced Thematic Mapper (2000) Bands 1, 4, 5

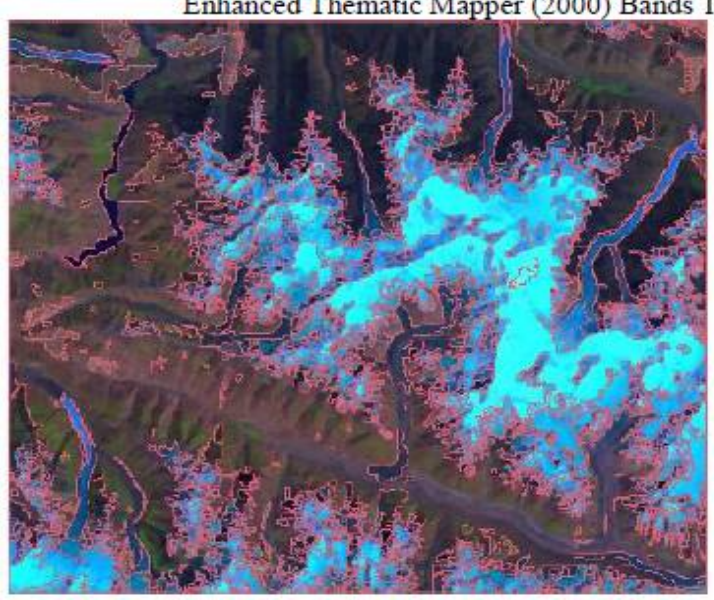

Enhanced Thematic Mapper (2010) Bands 1, 4, 5

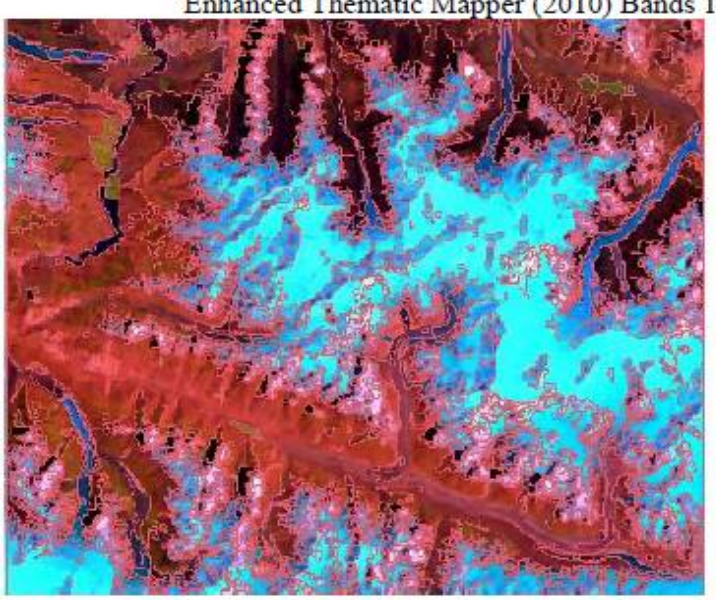

Enhanced Thematic Mapper (2012) Bands 1, 4, 5

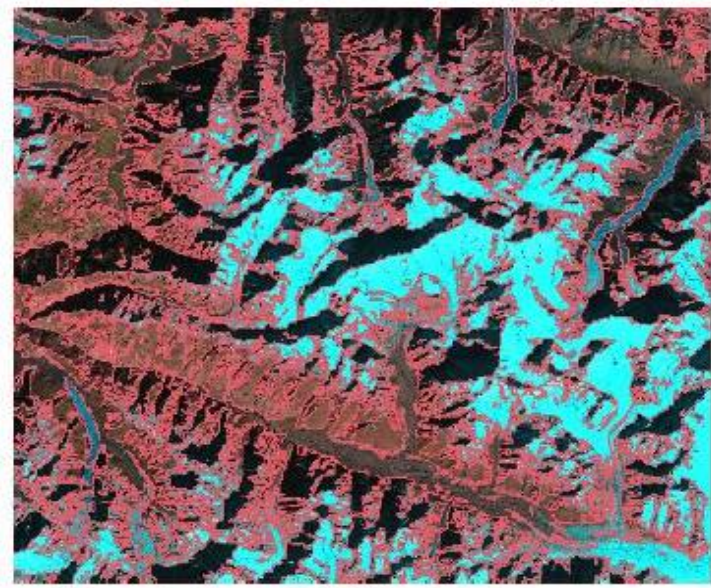

Enhanced Thematic Mapper (2000) Bands 3, 4, 5

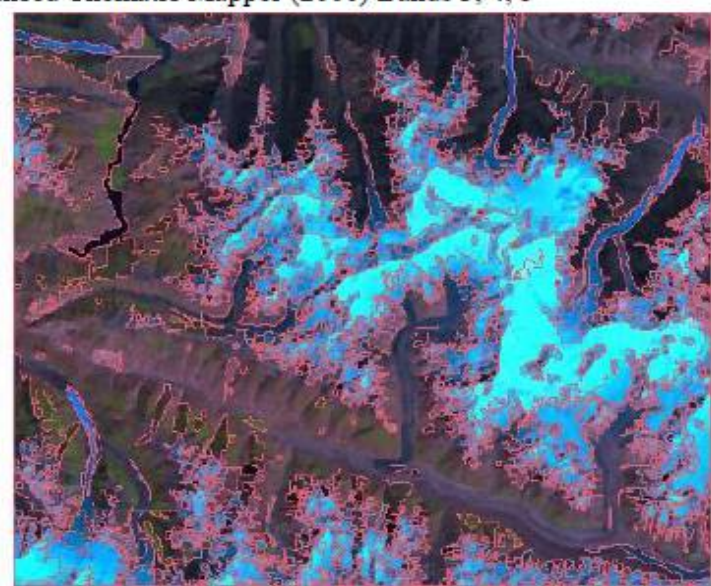

Enhanced Thematic Mapper (2010) Bands 3, 4, 5

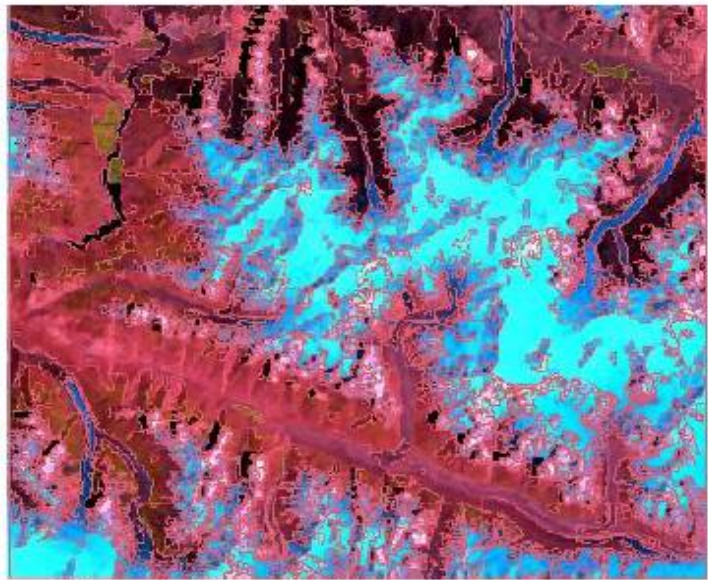

Enhanced Thematic Mapper (2012) Bands 3, 4, 5

Fig. 1 Segmentation results of Landsat enhanced thematic mapper data set. 


\section{Object Oriented Analysis of Landsat TM/ETM 1992 - 2012 Data}
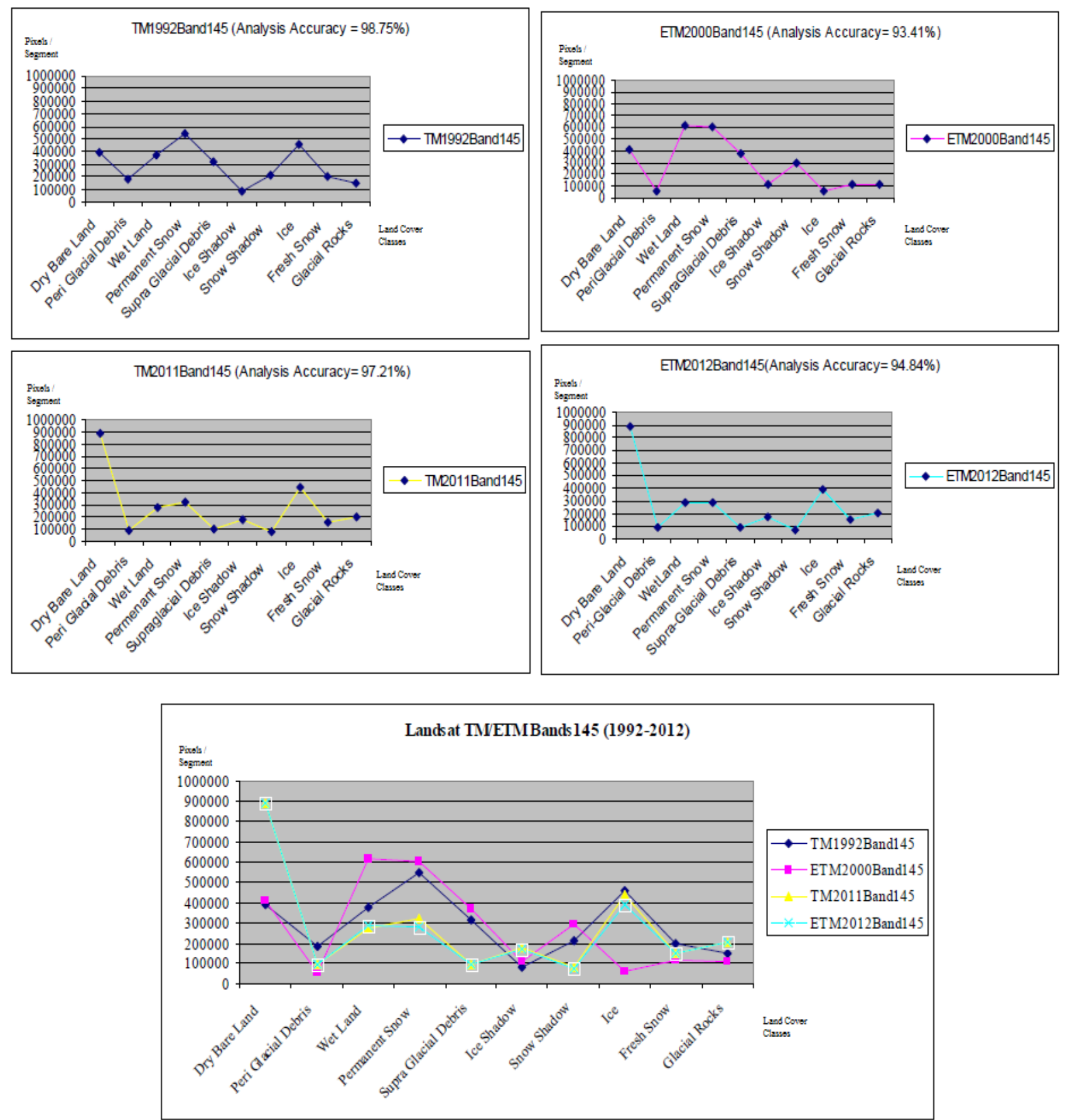

Fig. 2 Landsat blue, near and mid infrared bands analysis accuracy graphs as an example on object based analyse (besides was also (blue+near infra red +mid infra read) and (red+near infrared + mid infra) analysed). 


\section{Conclusion}

Data analysis clearly indicates the changes in vegetation and non-vegetation parts of the study area. Meteorological record of last two decades clearly shows increase in the average temperature particularly during last decade from the year 2000 to year 2010. Slow but gradual adverse effects of climate changes on the region are visible in the statistical as well as in analysed image data.

Landsat imagery's interpretation either by traditional classification approach or by using any specialized algorithm like NDSI or NDVI disclosed this fact that change in the climate directly affected ice/snow cover, vegetation and geo-morphological structure of the study area in one way or another. Remotely sensed data analysis procedures often follows statistical parameters and lacks the ability to interpret structural/contextual properties of the land cover objects particularly urban areas or man-made features like buildings, roads etc. But emerging object oriented analysis approaches use spatial and thematic reasoning approach to provid the opportunity for structural analysis [25]. As depletion of the snow/ice cover leads to slightly increase in the vegetation ratio, this was proven in the vegetation index analysis of Landsat Imagery from 1992-2011. Recent calamities like flooding, earthquakes, landslides and drought provides ample evidence of climate changes in the region.

Considerable decrease in the snow/ice cover observed in the analysed data from 1992 to 2012. Although there's little change observed in other land cover classes of the study area, but analysed data calculations shows from 2000 to 2012 glaciers in the Hispar and Hunza Nagar faced serious problems due to global warming.

The findings are as following:

(1) Object based analysis shows better accuracy ratio as compared to pixel-based analysis. With the help of object based analysis, various non-vegetative classes were identified in the Landsat imagery;

(2) Slow but gradual depletion of snow/ice cover was observed in the study area of Karakoram region;

(3) Massive landslides/mudslides phenomena observed in the study area in 2010 and 2012 in Landsat imagery. Artificial lake on the river Hunza was clearly visible in TM and ETM 2010, 2011 and 2012 imagery. Therefore, it was easy to figure out the actual damage done by the landslide episode in this area after the analysis;

(4) Snow and ice melting catalyse floods, mudslides, landslides and lake outburst episodes in the area during the last two decades. This can be clearly observed in the analysed imagery and survey data as well;

(5) Vegetation area increased due to glacial retreat. Therefore, gradual increase in the vegetation can be observed from the year 1992 to 2011.

\section{Acknowledgement}

This study was performed with the support from Linkoping University and Swedish Defence University. Furthermore, the authors have been provided with data from United States Geological Survey and University of Maryland land cover portal between several other-no more mentioned and no forgotten. This work has also been presented at International Environmental Modelling and Software Society (iEMSs) 7th Intl. Congress on environmental modelling and software, San Diego, CA, USA, 2014.

\section{References}

[1] Trianni, G., Dell, Acqua, F., and Gamba, P. 2007. "Damage Detection at Different Scales from SAR and QuickBird Imagery for the 2003 Boumerdes, Algeria, earthquake." In 5th International Workshop on Remote Sensing for Disaster Management, 10-12.

[2] Sahin, H., Tophan, H., Karakis, S., and Marangoz, A. M. 2006. Comparison of Object Oriented Image Analysis and Manual Digitizing for Feature Extraction, ZKU. Zonguldak, Turkey: Engineering Faculty.

[3] Humanitarian Response. 2013. "Natural Disasters Data Pakistan 1935-2011." Accessed September 11, 2013. 

Karakoram Range Northern Pakistan

http://www.pakresponse.info/LinkClick.aspx?fileticket= DmiKavwzcm4\%3D\&tabid=78\&mid=482.

[4] Rakshan, R., Arshad, A., and Naveed, M. M. Tariq. 2008. Preparatory Assessment Report on Community Based Survey for the Assessment of Glacial Lake Outburst Flood Hazards (GLOFs) in Hunza River Basin. Pakistan: National Agriculture Research Centre Islamabad.

[5] Chen, X. L., Zhao, H. M., Li, P. X., and Yin, Z. Y. 2006. "Remote Sensing Image-Based Analysis of the Relationship between Urban Heat Island and Land Use/Cover Changes." Remote Sensing of Environment 104 (2): 133-146.

[6] Sohail, B., Rasul, G., and Kazmi, D. H. 2011. "Evaluation of Projected Minimum Temperature for Northern Pakistan." Pakistan Journal of Meteorology 7 (14): 63-70.

[7] Bashir, F., and Rasul, G. 2010. "Estimation of Water Discharge from Gilgit Basin Using Remote Sensing, GIS and Runoff Modeling." Pakistan Journal of Meteorology 6 (12): 97-113.

[8] Butt, J. M., and Farooq, M. I. 2008. "Impact of Climate Variability on Snow Cover: A Case Study of Northern Pakistan." Pakistan Journal of Meteorology 5 (10): 53-64.

[9] Gamanya, R., Maeyer, P., and Dapper, M. 2009. Object Oriented Change Detection for the City of Harare, Zimbabwe. Belgium: Elsevier Publishers.

[10] Khalsa, S. J. S., Dyurgerov, M. B., Khromova Tatiana Raup, H. B., and Barry, R. G. 2004. "Space-Based Mapping of Glacier Changes Using Aster and GIS Tools." IEEE Transactions on Geosciences and Remote Sensing 42: 2177-2183.

[11] Aplin, P., and Smith, G. M. 2008. "Advances in Object-Based Image Classification." In Proceeding of Commission VII ISPRS Congress, 37.

[12] Price, P. Kevin, Guo, Xu, lin, and Stiles, M. J. 2002. "Optimal Landsat TM Band Combinations and Vegetation Indices for Discrimination of Six Grassland Types in Eastern Kansas." International Journal of Remote Sensing 23: 1-12.

[13] Blaschke, T., Lang, S., Lorup, E., Strobl, J., and Zeil, P. 2006. "Object Oriented Image Processing in an Integrated GIS/Remote Sensing Environment and Perspectives for Environmental Applications." In ZGIS, Zentrum Fur Geographische Informations Verarbeitung, 555-570.

[14] Hay, G. J., and Castilla, G. 2006. "Object Based Image Analysis: Strengths, Weaknesses, Opportunities and Threats (SWOT); The International Archives of Photogrammetry." In Remote Sensing and Spatial Information Sciences, 75-89.

[15] DeKok, R., Schneider, T., Baatz, M., Ammer, U. 2006. Object Based Image Analysis of High Resolution Data in
Alpine Forest Area. Freising, Germany: Lehrstuhl Fur Landnutzungsplanung Und Naturschutz Am Hochanger.

[16] Ouma, O., Yashon, Josaphat, S. S., and Tateishi, Ryutaro. 2008. "Multi-scale Remote Sensing Data Segmentation and Post Segmentation Change Detection Based on Logical Modelling: Theoretical Exposition and Experimental Results for Forestland Cover Change Analysis." Computers \& Geosciences 34 (7): 715-737.

[17] Lewinski, S. 2006. "Object Oriented Classification of Landsat ETM+ Satellite Image." Journal of Water and Land Development 10: 91-106.

[18] Moutinho, C., Pinho, D., Fonseca, L. M. G., Korting, T. S., Almeida, C. M., and Kux, H. J. H. 2006. "Land-Cover Classification of an Intra-urban Environment Using High-Resolution Images and Object-Based Image Analysis." International Journal of Remote Sensing 33 (19): 5973-5995.

[19] Flores, E. S., Caravantes, R. D., Chavez, J., and Olivas, G. A. 2009. "GIS Improved Object Based Classification for Land Use/Cover Change Detection in a Human Altered Deciduous Forest Environment." In ASPRS Annual Conference Baltimore Maryland USA.

[20] Laliberte, S. Andrea, Rango Albert, Havstad M. Kris, Paris, F. Jack, Beck F. Reldon, and Mcneely, Robet. 2004. "Object Oriented Image Analysis for Mapping Shrub Encroachment from 1937 to 2003 in Southern New Mexico." Remote Sensing of Environment 93: 198-210.

[21] Esbah, H., Baris, K., Bulent, D., and Birsen, K. 2010. "Changing Land Covered Characteristics of a Developing Town: A Case Study of Didim, Turkey." Journal of Costal Research 26 (2): 274-282.

[22] WMO Report 1108. WMO, Digital (Free), Hard Copy. ISBN: 978-92-63-11108-1.

[23] Hussain, S. S., Muaddsser, M., Sheikh, M., and Manzoor, N. 2005. "Climate Change and Variability in Mountain Regions of Pakistan, Implication for Water and Agriculture." Pakistan Journal of Meteorology 2 (4): 75-90.

[24] Zhan, Q., Molenaar, M., and Tempfli, K. 2001. Hierarchical Image Object-Oriented Structural Analysis toward Urban Landuse Classification Using High Resolution Imagery and Airborne LIDAR Data. Netherlands: International Institute for Geo-information Sciences and Earth Observation (ITC).

[25] Khan, A. D., Iqbal, Naveed, I., and Arshad, A. 2009. "Climate Change Impact Assessment of Glaciers Using Remote Sensing Technology_A Case Study of Karambar Glacier Pakistan." Pakistan Council of Research in Water Resources (PCRWR) and National Agriculture Centre (NARC). Accessed March 30, 2010. http://geoportal.icimod.org/symposium2010/Downloads/ SymposiumPosters/ PDFDownload/81.pdf. 